\title{
The Moderating Role of Personal Profiles on the Relationship between Multicultural Awareness and Self-Regulated Learning
}

\author{
Fifi Khoirul Fitriyah ${ }^{1,2(\bowtie)}$, M. Sukron Djazilan ${ }^{1}$, Nopriadi Saputra ${ }^{3}$, Mokhamad Sodikin $^{4}$, Umu \\ Anugerah Izzati ${ }^{5}$ \\ ${ }^{1}$ Nahdlatul Ulama University of Surabaya, Indonesia \\ ${ }^{2}$ The State University of Malang, Indonesia \\ ${ }^{3}$ Bina Nusatara University, Indonesia \\ ${ }^{4}$ Universitas Indonesia, Indonesia \\ ${ }^{5}$ Universitas Negeri Surabaya, Indonesia \\ ${ }^{(凶)}$ fifi@unusa.ac.id
}

\begin{abstract}
Multicultural awareness is very crucial for every student, as well as self-regulated learning. Until now, research on these two variables is still minimal. Moreover, there are no studies that examine the factors that influence the relationship between the two variables. This study aims to explore the relationship between multicultural awareness and self-regulated learning in students and discuss the role of students' personal profile in the relationship between the variables. The respondents of this study were 165 students of the City of Surabaya, Indonesia. The structural equation model is used for data analysis techniques. The results showed that hypothesis 1 was accepted, meaning a positive and significant effect of multicultural awareness on self-regulated learning. The path coefficient was 0.284 , while the t-statistics were more significant than $1.96(2,544)$ or p-values less than $0.05(0.011)$. Whereas in hypothesis 2 , it is rejected, the path coefficient is -0.230 while the $t$-static is less than $1.96(1,811)$ or the p-value is more significant than 0.05 (0.071). In conclusion, personal profiles do not affect the relationship between multicultural awareness-ness and self-regulated learning. This study's recommendation is to provide information on need assessments useful in determining appropriate counseling strategies at the University.
\end{abstract}

Keywords - multicultural awareness, personal profile, self-regulated learning, student, university 


\section{Kresna Social Science and Humanities Research}

Proceedings of the International Conference On Ummah:

Digital Innovation, Humanities And Economy (ICU: DIHEc) 2020

https:/doi.org/10.30874/ksshr.3

\section{Introduction}

Self-regulated learning is a study that has been widely discussed by education academics in recent years. Even so, there are still many topics that have not been explained in detail, especially those related to the principles of implementing self-

regulated learning on specific issues. One issue is learning in a multicultural context. It is undeniable that multicultural students' distribution has fulfilled most classes in 21 stcentury learning, especially students at universities where they come from cities or even different countries. Research in Australia states that each student has a different learning strategy depending on their cultural background, meaning that culture significantly influences the learning strategy chosen by students (Purdie \& Hattie, 1996).

The issue of multiculturalism becomes an interesting issue, especially in industrial revolution 4.0, which emphasizes the importance of collaborative relationships in learning. This is evidenced by recent experiments that students in groups with students from different countries have exceptional learning achievements than students in groups with students from the same country (Ogrutan et al., 2019). This proves that this multiculturalism aspect has a positive impact on increasing student creativity, so the construct of multicultural awareness needs to be further investigated. Moreover, the study results recommend the importance of information about multiculturalism in a university that is used to find the formulation of treatment for them (Hladik \& Jadama, 2016).

Speaking of multiculturalism, Indonesia is a very multicultural country with 1,340 ethnic groups and six government-recognized religions. Even in the same group of people, each individual has diverse cultures and values (Kececi \& Eksi, 2019). So that cultural diversity is a necessity that can not be avoided. On the one hand, the multicultural dimension is considered capable of creating a passionate and open community to ideas, perspectives, and innovations (Yeh et al., 2004). Based on the research results in various countries, multiculturalism often causes misconceptions in communication, causing misunderstanding and end conflicts (Cameron, 2010; Wendt \& Gone, 2016).

Misunderstandings generally occur due to the emergence of negative stigma between groups of people with different cultures. The key to reducing these negative impacts is to increase understanding and commitment to mutual agreement. Increasing knowledge and acceptance among individuals in different groups is proven to reduce the appearance of negative stigmas (Hayes et al., 2004; Horenczyk \& Tatar, 2002; Martínez, 2014). On the other hand, multiculturalism perceptions have a positive effect on self-regulated learning (Hladík et al., 2012).

Several studies have proven a positive relationship between multicultural alawareness and self-regulated learning (Anyichie et al., 2016; Anyichie \& Butler, 2017; Hladík et al., 2012; Zeleke et al., 2018). However, the study results did not explain what factors influenced the relationship between the two variables. On the other hand, these factors are needed as consideration for giving treatment. The study results emphasize the importance of considering every individual's aspect based on his background (Anyichie et al., 2016; Anyichie \& Butler, 2017). Thus this research fills this gap by identifying the student's profile concerning the relationship between multicultural awareness and self-regulated learning. The personal profile that becomes the moderator variable in this study is gender and scientific background, namely exact science or social science.

This study aimed to examine the relationship between multicultural awareness and self-regulated learning in students and examine students' profiles of these relationships. The results of this research can later be used as a rigorous need 


\section{Kresna Social Science and Humanities Research}

Proceedings of the International Conference On Ummah: Digital Innovation, Humanities And Economy (ICU: DIHEc) 2020 https:/doi.org/10.30874/ksshr.3

assessment in determining strategies to increase multicultural awareness and selfregulated learning through counseling services at the University.

\section{$2 \quad$ Methodology}

This article is based on exploratory qualitative research by using the Partial Least Square Structural Equation Modeling (PLS-SEM) approach. The second-order type is used for the research model, which consists of measurement and structural models. Measurement models explain the relationship between variables, its dimensions, and its indicators. The structural model describes the relationship between variables and is used for hypothesis testing.

\subsection{Demographic Summary}

The research sample was 165 students who studied at the campus in Surabaya City, East Java, Indonesia (see Table 1). This sample size is more than enough as a sample of endogenous construct models in two directions. The minimum number of samples determined is a minimum of 52 respondents, a significance level of $0.05,80 \%$ statistical power and a minimum of R2 $=0.25$ (Hair et al., 2014).

Table 1. Demographic Characteristic of Respondent

\begin{tabular}{|c|c|c|c|c|c|c|}
\hline \multirow{3}{*}{ VARIABLE } & \multicolumn{6}{|c|}{ EXACT SCIENCE } \\
\hline & \multicolumn{2}{|c|}{ MALE (1) } & \multicolumn{2}{|c|}{ FEMALE (2) } & \multicolumn{2}{|c|}{ TOTAL } \\
\hline & MEAN + SD & MIN-MAX & MEAN + SD & MIN-MAX & MEAN + SD & MIN-MAX \\
\hline AGE & $19,619+0,920$ & $18-22$ & $19,545+0,938$ & $18-22$ & $19,574+0,923$ & $18-22$ \\
\hline SA & $21,190+2,874$ & $16-28$ & $21,727+2,503$ & $16-26$ & $21,518+2,640$ & $16-28$ \\
\hline CA & $25+2,366$ & $21-29$ & $24,575+2,806$ & $17-30$ & $24,740+2,629 \mid$ & $17-30$ \\
\hline LM & $30,381+3,057$ & $27-35$ & $29,363+2,395$ & $23-35$ & $29,759+2,691$ & 23-35 \\
\hline LP & $32,571+3,585$ & $27-40$ & $32,303+3,513$ & $25-38$ & $32,407+3,51$ & $25-40$ \\
\hline LSD & $77,809+8,328$ & $56-91$ & $76,787+7,179$ & $64-95$ & $77,185+7,786$ & $56-95$ \\
\hline \multirow[t]{2}{*}{ LD } & $18,142 \pm 4,065$ & $10-25$ & $20,333 \pm 3,068$ & $14-29$ & $19,481 \pm 3,617$ & $10-29$ \\
\hline & \multicolumn{6}{|c|}{ SOCIAL SCIENCE } \\
\hline \multirow[t]{2}{*}{ VARIABLE } & \multicolumn{2}{|c|}{ MALE (1) } & \multicolumn{2}{|c|}{ FEMALE (2) } & \multicolumn{2}{|c|}{ TOTAL } \\
\hline & MEAN + SD & MIN-MAX & MEAN + SD & MIN-MAX & MEAN + SD & MIN-MAX \\
\hline AGE & $19,666+0,832$ & $19-21$ & $19,583+1,253$ & $18-29$ & $19,603+1,162$ & $18-29$ \\
\hline SA & $22,185+2,631$ & $17-27$ & $21,404+2,9$ & $13-27$ & $21,594+2,845$ & $13-27$ \\
\hline CA & $24,925+2,8$ & $19-30$ & $23,964+2,979$ & $17-29$ & $24,198+2,953$ & $17-30$ \\
\hline LM & $29,481+2,833$ & $22-35$ & $29,452+2,456$ & $22-35$ & $29,459+2,539$ & $22-35$ \\
\hline LP & $32,074+3,636$ & $20-39$ & $31,988+3,381$ & $24-40$ & $32,009+3,428$ & $20-40$ \\
\hline LSD & $77,444+6,24$ & $65-91$ & $76,857+5,536$ & $61-91$ & $77+5,706$ & 61-91 \\
\hline LD & $18,296+4,083$ & $21-27$ & $19,761+2,969$ & $13-27$ & $19,405+3,312$ & $7-27$ \\
\hline
\end{tabular}




\section{Kresna Social Science and Humanities Research \\ Proceedings of the International Conference On Ummah: Digital Innovation, Humanities And Economy (ICU: DIHEc) 2020 https:/doi.org/10.30874/ksshr.3}

\subsection{Materials and Method}

This study uses two self-report questionnaires; they are Multicultural Awareness Scale (MAS) and Self-Regulated Learning Perception Scale (SRLPS). Both questionnaires have strong validity and reliability.

This data was taken after lectures took place by the contributing lecturers in this study. Respondents were asked to fill out questionnaires using pencil and paper to measure multicultural awareness, self-regulated learning, and demographics characteristics. All respondents in this study agreed as research subjects. Participation in this study is voluntary, and there are no rewards of any kind, either credit class or monetary reward. Ethical approval is obtained through lecturers and authorized officials at the University.

The dimensions of Self-Regulated Learning are measured using the Indonesian version of SRLPS. There are 41 items in it, divided into four aspects: (1) Motivation and Action to Learning, 7 items. (2) Planning and Goal Settings, 8 items. (3) Strategies for Learning and Assessment, 19 items, and (4) Lack of Self-Direction, 7 items. Respondents were asked to indicate how much each item described themselves on a 5-point Likert scale. Complimentary items start from 1 (highly inappropriate) to 5 (very appropriate), and vice versa. Cronbach's alpha for this study was 0.609 (See Table 2).

Multicultural Awareness dimensions are measured using the Indonesian version of MAS. There are 12 items in it, divided into two aspects, namely; (1) self-awareness, 6 items, and (2) cultural awareness, 6 items. Respondents were asked to indicate how much each item represented themselves on a 5-point Likert scale. Positive items start from 1 (highly inappropriate) to 5 (very appropriate), and vice versa. Cronbach's alpha for this study was 0889 (See Table 1).

\subsection{Measurement's Validity and Reliability}

Model measurements are shown in Figure 1. Calculation of instrument validity using Smart PLS, all items with loading factors below 0.6, are removed from the model. Based on the parameters in Table 2 and Table 3, the validity and reliability of the measurement model can be analyzed. For validity analysis, this study uses convergent and discriminant validity. Convergent validity is based on Average Variance Extracted (AVE). AVE value for most constructs is above 0.5 , meaning that this measurement model has good concurrent validity. Discriminant validity is analyzed using the numbers in Table 3. In the diagonally bold numbers is the square root of AVE. These numbers are higher than other list numbers, meaning that this measurement model has good discriminant validity.

For reliability analysis, this study uses internal consistency and composite reliability. Internal consistency is explained using Cronbach's Alpha. Ideally, the composite reliability and Cronbach's Alpha values are more than 0.7. However, based on (Hair et al., 2014), for explanatory research, if constructs or items have a loading factor or Cronbach's Alpha or composite reliability between $0.6-0.7$, then constructs or items can still be used in the model. Table 2 shows that Cronbach's Alpha is only in the SelfAwareness dimension below 0.6 , but the composite reliability states that all dimensions 


\section{Kresna Social Science and Humanities Research}

Proceedings of the International Conference On Ummah:

Digital Innovation, Humanities And Economy (ICU: DIHEc) 2020

https:/doi.org/10.30874/ksshr.3

have values above 0.6 . This indicates that the measurement model is right for composite reliability but lacks internal consistency reliability in one dimension. In general, this measurement model is valid and reliable for the constructs of multicultural awareness and self-regulated learning.

Table 2. Validity and Reliability

\begin{tabular}{|c|c|c|c|c|c|}
\hline Dimension & Item & $\begin{array}{c}\text { Outer } \\
\text { Loading }\end{array}$ & $\begin{array}{c}\text { Cronbach's } \\
\text { Alpha } \\
\end{array}$ & $\begin{array}{l}\text { Composite } \\
\text { Reliability }\end{array}$ & AVE \\
\hline Multicultural Awareness & & & 0,609 & 0,765 & 0,401 \\
\hline \multirow{2}{*}{ Self-Awareness } & SA01 & 0,759 & \multirow{2}{*}{0,206} & \multirow{2}{*}{0,716} & \multirow{2}{*}{0,557} \\
\hline & SA06 & 0,734 & & & \\
\hline \multirow{3}{*}{ Cultural Awareness } & CA03 & 0,761 & \multirow{3}{*}{0,728} & \multirow{3}{*}{0,847} & \multirow{3}{*}{0,649} \\
\hline & CA04 & 0,832 & & & \\
\hline & CA05 & 0,822 & & & \\
\hline Self-Regulated Learning & & & 0,897 & 0,912 & 0,360 \\
\hline \multirow{4}{*}{$\begin{array}{l}\text { Motivation and Action } \\
\text { Learning }\end{array}$} & MO02 & 0,825 & \multirow{4}{*}{0,756} & \multirow{4}{*}{0,845} & \multirow{4}{*}{0,578} \\
\hline & MO04 & 0,816 & & & \\
\hline & MO05 & 0,733 & & & \\
\hline & MO07 & 0,656 & & & \\
\hline \multirow{6}{*}{ Planning and Goal Setting } & PL01 & 0,691 & \multirow{6}{*}{0,834} & \multirow{6}{*}{0,883} & \multirow{6}{*}{0,603} \\
\hline & PL02 & 0,775 & & & \\
\hline & PL04 & 0,702 & & & \\
\hline & PL05 & 0,825 & & & \\
\hline & PL06 & 0,811 & & & \\
\hline & PL08 & 0,731 & & & \\
\hline \multirow{8}{*}{ Strategies for Learning } & ST05 & 0,626 & \multirow{8}{*}{0,850} & \multirow{8}{*}{0,850} & \multirow{8}{*}{0,490} \\
\hline & ST06 & 0,717 & & & \\
\hline & ST08 & 0,744 & & & \\
\hline & ST10 & 0,701 & & & \\
\hline & ST13 & 0,747 & & & \\
\hline & ST15 & 0,717 & & & \\
\hline & ST16 & 0,638 & & & \\
\hline & ST17 & 0,742 & & & \\
\hline \multirow{2}{*}{ Lack of Self-Direction } & SD01 & 0,885 & \multirow[b]{2}{*}{0,688} & \multirow[b]{2}{*}{0,865} & \multirow[b]{2}{*}{0,761} \\
\hline & SD03 & 0,861 & & & \\
\hline
\end{tabular}

Table 3. Discriminant Validity 


\section{Kresna Social Science and Humanities Research}

Proceedings of the International Conference On Ummah: Digital Innovation, Humanities And Economy (ICU: DIHEc) 2020 https:/doi.org/10.30874/ksshr.3

\begin{tabular}{|c|l|c|c|c|c|c|c|c|c|}
\hline & \multicolumn{1}{|c|}{ Dimensions } & 1 & 2 & 3 & 4 & 5 & 6 & 7 & 8 \\
\hline 1 & $\begin{array}{l}\text { Cultural Aware- } \\
\text { ness }\end{array}$ & 0,805 & & & & & & & \\
\hline 2 & $\begin{array}{l}\text { Motivation and } \\
\text { Action Learning }\end{array}$ & 0,137 & 0,760 & & & & & & \\
\hline 3 & $\begin{array}{l}\text { Planning and } \\
\text { Goal Setting }\end{array}$ & 0,180 & 0,506 & 0,776 & & & & & \\
\hline 4 & $\begin{array}{l}\text { Strategies for } \\
\text { Learning }\end{array}$ & 0,272 & 0,515 & 0,654 & 0,700 & & & & \\
\hline 5 & $\begin{array}{l}\text { Multicultural } \\
\text { Awareness }\end{array}$ & 0,933 & 0,211 & 0,226 & 0,320 & 0,641 & & & \\
\hline 6 & Self-Awareness & 0,234 & 0,252 & 0,192 & 0,239 & 0,567 & 0,747 & & 0,600 \\
\hline 7 & $\begin{array}{l}\text { Self-Regulated } \\
\text { Learning }\end{array}$ & 0,230 & 0,740 & 0,858 & 0,898 & 0,290 & 0,252 & 0,403 & 0,873 \\
\hline 8 & $\begin{array}{l}\text { Lack of Self-Di- } \\
\text { rectedness }\end{array}$ & $-0,095$ & 0,326 & 0,274 & 0,230 & $-0,100$ & $-0,054$ & 0,403 \\
\hline
\end{tabular}

\subsection{Data Analysis}

In this study, Structured Equation Modeling (SEM) uses AMOS software to test the overall hypotheses due to the theoretical model's mediating structure. The links between constructs of a structural equation model may be estimated with independent regression equations or through more involved approaches (Ullman, 2006; Ullman \& Bentler, 2003). SEM includes confirmatory factor analysis, path analysis, partial least squares path analysis, LISREL and latent growth modeling. Thus, SEM will be effective to test the developed hypotheses in this research. The research hypothesis is:

- H1: Multicultural awareness does impact on self-regulated learning significantly

- H2: Personal profile does impact on the relationship between multicultural awareness and self-regulated learning.

\section{$3 \quad$ Result and Discussion}

In SEM statistical analysis, the structural equation model is the second most important process. After validating the measurement model, the relationships between the variables can be assessed. The structural model provides specific details on the relationship between the independent or exogenous variables and the dependent or endogenous variables. Firstly, it focuses on the overall fit model, followed by the size, direction and significance of the hypothesized parameter estimates. This is shown in a oneheaded path diagram. The final stage involved confirmation of the structural model. This can be done by analyzing the proposed relationship between identified and assessed variables. To conduct effective SEM test, the paths between the modified model variables are redraw. The retest of the correlation between the model items could improve the model fit by reducing the indirect or hidden relationship between the items, i.e., enhancing the $\mathrm{x} 2$ value. All CFA (factors loading, reliability-fit, and fit indices) 


\section{Kresna Social Science and Humanities Research}

Proceedings of the International Conference On Ummah Digital Innovation, Humanities And Economy (ICU: DIHEc) 2020 https:/doi.org/10.30874/ksshr.3

test for the final model provides accurate records. Hence, this study is carried out depending on the entire items in the modified model. Figure 1 illustrates the final SEM model, whereby the hypotheses could be tested.

In table 4, the structural model analysis results are (1) VIF Inner Model: Multicultural Awareness - Self-Regulated Learning is 1,000, and Self-Regulated Learning Multicultural Awareness is 1,000. All VIF values are less than 5, this indicates that there is no colinearity problem in the structural model. (2) Table 4 shows the outer path coefficient of the construct and its dimensions. Multicultural awareness has a value of self-awareness of 0.277 and cultural awareness of 0.877 . Self-regulated learning aspects have a value of motivation and action learning of 0.742 , planning and goal setting of 0.861 , strategies for learning of 0.900 , and lack of self-direction of 0.398 . The highest score is self-regulated learning for learning (0.900) strategies, and the lowest is the lack of self-direction (0.398). All constructs have a path coefficient score with t-Statistics more than 1.96 and $\mathrm{p}$-Value $=0.000$. This shows that each construct has a significant correlation with its dimensions.

Tabel 4. Outer Path Coefficient

\begin{tabular}{|c|c|c|c|c|c|}
\hline Variable & Dimensions & $\begin{array}{c}\text { Path } \\
\text { Coefficient }\end{array}$ & t-Statistic & p-Values & Result \\
\hline \multirow{2}{*}{$\begin{array}{l}\text { Multicul- } \\
\text { tural } \\
\text { Awareness }\end{array}$} & $\begin{array}{l}\text { Self-Aware- } \\
\text { ness }\end{array}$ & 0,277 & 3,792 & 0,000 & Significant \\
\hline & $\begin{array}{l}\text { Cultural } \\
\text { Awareness }\end{array}$ & 0,877 & 16,880 & 0,000 & Significant \\
\hline \multirow[t]{4}{*}{$\begin{array}{l}\text { Self-Regu- } \\
\text { lated } \\
\text { Learning }\end{array}$} & $\begin{array}{l}\text { Motivation } \\
\text { and Action } \\
\text { Learning }\end{array}$ & 0,742 & 18,529 & 0,000 & Significant \\
\hline & $\begin{array}{l}\text { Planning } \\
\text { and Goal } \\
\text { Setting }\end{array}$ & 0,861 & 38,875 & 0,000 & Significant \\
\hline & $\begin{array}{l}\text { Strategies } \\
\text { for Learn- } \\
\text { ing }\end{array}$ & 0,900 & 48,503 & 0,000 & Significant \\
\hline & $\begin{array}{l}\text { Lack of } \\
\text { Self-Direc- } \\
\text { tion }\end{array}$ & 0,398 & 3,967 & 0,000 & Significant \\
\hline
\end{tabular}

Tabel 5. Hypotesis Testing

\begin{tabular}{lcccc}
\hline \multicolumn{1}{c}{ Hypotesis } & $\begin{array}{c}\text { Path Coef- } \\
\text { ficient }\end{array}$ & t-Statistic & p-Values & Result \\
\cline { 2 - 2 } $\begin{array}{l}\text { H1: Multicultural Awareness } \\
\text { to Self-Regulated Learning }\end{array}$ & 0,284 & 2,544 & 0,011 & Accepted \\
\cline { 1 - 2 } $\begin{array}{l}\text { H2: Personal Profile to Rela- } \\
\text { tions of Multicultural Aware- }\end{array}$ & & & & \\
$\begin{array}{l}\text { ness and Self-Regulated Learn- } \\
\text { ing }\end{array}$ & $-0,230$ & 1,811 & 0,071 & Rejected
\end{tabular}




\section{Kresna Social Science and Humanities Research}

Proceedings of the International Conference On Ummah:

Digital Innovation, Humanities And Economy (ICU: DIHEc) 2020

https:/doi.org/10.30874/ksshr.3

Table 5 explains the results of hypothesis testing. $\mathrm{H} 1$ is accepted, and $\mathrm{H} 0$ is rejected because the path coefficient is 0.284 with t-Statistics $=2.544$ more than 1.96 or $p$-Value $=0.011$ less than 0.05 . That means there is a positive and significant impact on multicultural awareness of self-regulated learning. Individual perceptions of multiculturalism have a positive effect on self-regulated learning (Zeleke et al., 2018). The multicultural aspects in question are motivation, self-efficacy, metacognition, and attribution (Hladík et al., 2012; Hladik \& Jadama, 2016). Other researchers mention that self-regulated learning also needs to get an emphasis on the socio-cultural aspects, one of which is through the implementation of social regulation (Anyichie \& Butler, 2017). The results of this study support previous research. The conclusion is that multicultural aspects are essential points in self-regulated learning. Besides, the results of this study also fill the gaps in previous research. Other researchers mention that self-regulated learning also needs to get an emphasis on the socio-cultural aspects, one of which is through the implementation of social regulations. Of course, this implementation cannot be separated from the multicultural element of awareness (Anyichie \& Butler, 2017). While every student in a learning situation needs self-regulated learning.

The results of testing the second hypothesis in table 4 stated rejected or $\mathrm{H} 0$ accepted. $\mathrm{H} 2$ is rejected because the path coefficient is -0.230 with t-Statistic 1.811 or less than 1.96 , and $\mathrm{p}$-Value $=0.071$ is more than 0.05 . The sources state that the analysis results tolerate p-value up to a maximum of 0.05 (Hair et al., 2014). The intended personal profile was the gender-profile and science background (exact/social), meaning that the two profiles did not affect the relationship between multicultural awareness and selfregulated learning.

Discourse represents language, ideas, and images, which form a person's understanding of the world. In counseling, conversation determines the outcome of clinical practice (Ratts \& Greenleaf, 2018). Other research states that understanding values, awareness, and knowledge about multiculturalism alone is, in fact, not enough to be used to conduct effective counseling interventions in plural groups. Still, there need to be techniques that are emphasized (Rodriguez \& Eugene Walls, 2000). On the other hand, the application of this technique requires personal identification related to student characteristics. This study's results contribute to gender profiles and background knowledge that need not be considered in efforts to increase self-regulated learning concerning multicultural awareness in counseling. Furthermore, the study results show that multiculturalism in psychotherapy and counseling is still very little discussed (BasSarmiento et al., 2019; Rodriguez \& Eugene Walls, 2000). The results of this study can be the basis for implementing multicultural counseling at the University. Community colleges at the University are used based on their abilities as gateways and gatekeepers to tertiary education. It is a power structure that can provide social and economic opportunities through achieving degrees for underrepresented groups. Therefore, the implications for counselors in various settings are highlighted, along with the implications for future research (Brawner, 2018). Other study also recommends the importance of developing multicultural counseling at universities (Pietrantoni \& Glance, 2019). 


\section{Kresna Social Science and Humanities Research}

Proceedings of the International Conference On Ummah: Digital Innovation, Humanities And Economy (ICU: DIHEc) 2020 https:/doi.org/10.30874/ksshr.3

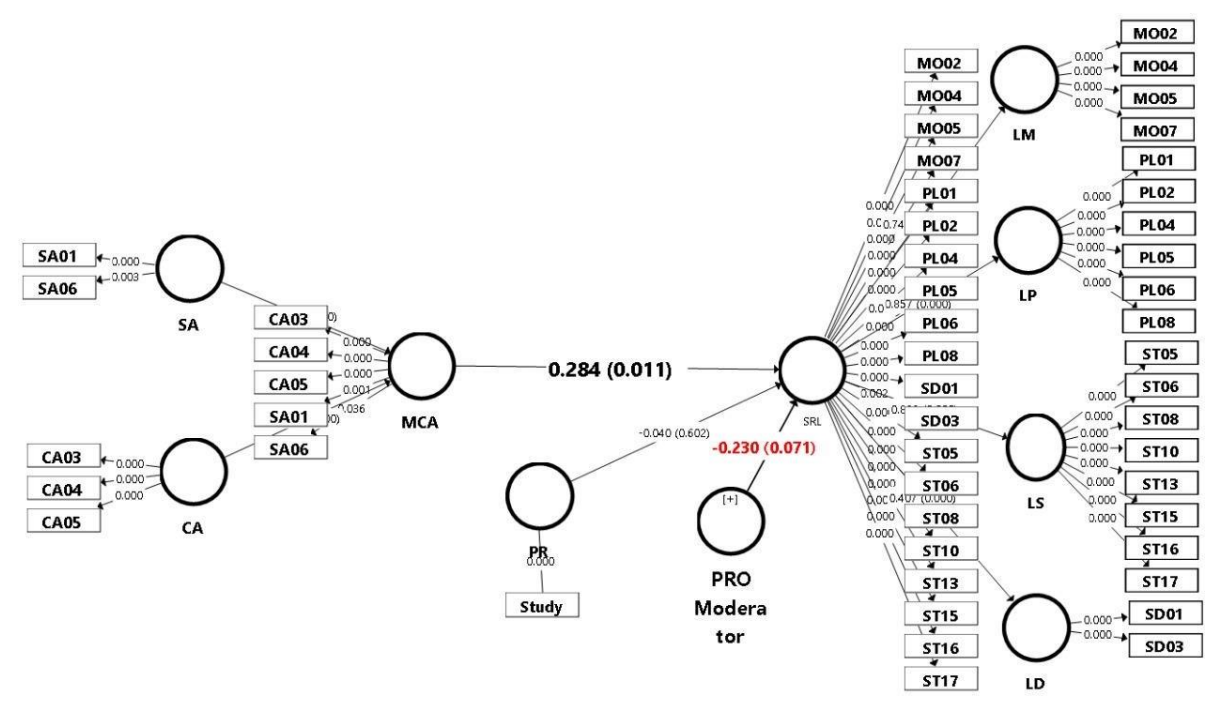

Figure 1. Research Model

\section{Conclusion}

This study examines the relationship between multicultural awareness and self-regulated learning in students and examines the role of student personal profiles in the relationship between the two variables. The results found that there was a positive and significant impact on multicultural awareness of self-regulated learning. However, students' personal profile proved not to have a significant effect on self-regulated learning. The personal profiles referred to were gender profiles and background knowledge (exact/social).

The results of this study's contribution is as a general need assessment in determining counseling interventions at the University. Although this study's personal profile proved not to affect self-regulated learning, it did not rule out the possibility to identify other personal profiles that were not covered in this study for further research. In addition, the contribution that is no less important is the results of this study as an initial assessment in determining counseling intervention at the University. Multicultural aspects are essential aspects in determining the success of many things, including the improvement of self-regulated learning references.

The following references are real ones, but have not been cited in this document. They have been pasted here for demonstration purposes.

Anyichie, A. C., \& Butler, D. L. (2017). A Culturally Responsive Self-Regulated Learning Framework. In P. Chen (Ed.), Journal of Chemical Information and Modeling. America Educational Research Association. https://doi.org/10.1017/CBO9781107415324.004 


\section{Kresna Social Science and Humanities Research}

Proceedings of the International Conference On Ummah:

Digital Innovation, Humanities And Economy (ICU: DIHEc) 2020

https:/doi.org/10.30874/ksshr.3

Anyichie, A. C., Yee, N., Perry, N., \& Hutchinson, L. (2016). Supporting Culturally Diverse Students with Self-Regulated Learning. Conference: Annual Meeting of Canadian Society for the Study of Education (CSSE). https://www.researchgate.net/profile/Aloysius_Anyichie/publication/321807336 _Supporting_Culturally_Diverse_Students_with_Self-

Regulated_Learning/links/5a32bb68458515afb6e0b439/Supporting-CulturallyDiverse-Students-with-Self-Regulated-Learning.pdf

Bas-Sarmiento, P., Fernández-Gutiérrez, M., Díaz-Rodríguez, M., Carnicer-Fuentes, C., Castro-Yuste, C., García-Cabanillas, M. J., Gavira-Fernández, C., MarteloBaro, M. de los Á., Paloma-Castro, O., Paublete-Herrera, M. del C., RodríguezCornejo, M. J., \& Moreno-Corral, L. (2019). Teaching empathy to nursing students: A randomised controlled trial. Nurse Education Today, 80(September 2018), 40-51. https://doi.org/10.1016/j.nedt.2019.06.002

Brawner, R. D. (2018). Variable Structure of Cultural Capital and Implications for Multicultural Counseling. Journal of Multicultural Counseling and Development, 46(3), 186-205. https://doi.org/10.1002/jmcd.12101

Cameron, L. (2010). Using the arts as a therapeutic tool for counselling - An Australian Aboriginal perspective. Procedia - Social and Behavioral Sciences, 5, 403-407. https://doi.org/10.1016/j.sbspro.2010.07.112

Hair, J., Hult, G. T. M., Ringle, C., \& Sarstedt, M. (2014). A Primer on Partial Least Squares Structural Equation Modeling (PLS-SEM). SAGE. https://doi.org/http://hdl.handle.net/1959.13/1063732

Hayes, S. C., Bissett, R., Roget, N., Padilla, M., Kohlenberg, B. S., Fisher, G., Masuda, A., Pistorello, J., Rye, A. K., Berry, K., \& Niccolls, R. (2004). The impact of acceptance and commitment training and multicultural training on the stigmatizing attitudes and professional burnout of substance abuse counselors. Behavior Therapy, 35(4), 821-835. https://doi.org/10.1016/S00057894(04)80022-4

Hladík, J., Hrbáčková, K., \& Vávrová, S. (2012). Individual Importance of Multicultural Competence in Relation to Components of Students' Self-regulated Learning. Procedia - Social and Behavioral Sciences, 69(Iceepsy), 341-349. https://doi.org/10.1016/j.sbspro.2012.11.419

Hladik, J., \& Jadama, L. M. (2016). Multicultural Competence of Helping Profession Students: Cross-cultural Comparison between Europe and Africa. Procedia Social and Behavioral Sciences, 217, 669-678. https://doi.org/10.1016/j.sbspro.2016.02.117

Horenczyk, G., \& Tatar, M. (2002). Teacher's attitudes toward multiculturalism and their perceptions of the school organizational culture. Teaching and Teacher Education, 18(4), 435-445. https://doi.org/10.1016/S0742-051X(02)00008-2

Kececi, B., \& Eksi, H. (2019). Multi-Cultural Counseling and Spiritual Interventions. 163-180. https://doi.org/10.12738/spc.2019.4.2.0066

Martínez, M. J. L. (2014). The Social and Emotional Competences in the Earliest Academic Training of Compulsory Education Teachers within Multicultural Contexts. Procedia - Social and Behavioral Sciences, 132, 549-556. https://doi.org/10.1016/j.sbspro.2014.04.352

Ogrutan, P. L., Machidon, A. L., \& Dinu, A. (2019). Is there a link between creativity and multiculturalism in education? TEM Journal, 8(2), 577-583. 


\section{Kresna Social Science and Humanities Research}

Proceedings of the International Conference On Ummah:

Digital Innovation, Humanities And Economy (ICU: DIHEc) 2020

https:/doi.org/10.30874/ksshr.3

https://doi.org/10.18421/TEM82-34

Pietrantoni, Z., \& Glance, D. (2019). Multicultural Competency Training of School Counselor Trainees: Development of the Social Class and Classism Training Questionnaire. Journal of Multicultural Counseling and Development, 47(1), 218. https://doi.org/10.1002/jmcd.12117

Purdie, N., \& Hattie, J. (1996). Cultural differences in the use of strategies for selfregulated learning. American Educational Research Journal, 33(4), 845-871. https://doi.org/10.3102/00028312033004845

Ratts, M. J., \& Greenleaf, A. T. (2018). Counselor-Advocate-Scholar Model: Changing the Dominant Discourse in Counseling. Journal of Multicultural Counseling and Development, 46(2), 78-96. https://doi.org/10.1002/jmcd.12094

Rodriguez, R. R., \& Eugene Walls, N. (2000). Culturally educated questioning: Toward a skills-based approach in multicultural counselor training. Applied and Preventive Psychology, 9(2), 89-99. https://doi.org/10.1016/S09621849(00)80008-6

Ullman, J. B. (2006). Structural equation modeling: Reviewing the basics and moving forward. Journal of Personality Assessment. https://www.tandfonline.com/doi/abs/10.1207/s15327752jpa8701_03

Ullman, J. B., \& Bentler, P. M. (2003). Structural equation modeling. Handbook of Psychology. https://onlinelibrary.wiley.com/doi/abs/10.1002/0471264385.wei0224

Wendt, D. C., \& Gone, J. P. (2016). Integrating Professional and Indigenous Therapies: An Urban American Indian Narrative Clinical Case Study. Counseling Psychologist, 44(5), 695-729. https://doi.org/10.1177/0011000016638741

Yeh, C. J., Hunter, C. D., Madan-Bahel, A., Chiang, L., \& Arora, A. K. (2004). Indigenous and interdependent perspectives of healing: Implications for counseling and research. Journal of Counseling and Development, 82(4), 410419. https://doi.org/10.1002/j.1556-6678.2004.tb00328.x

Zeleke, W. A., Karayiğit, C., \& Myers-Brooks, K. (2018). Using Self-Regulated Learning Strategies to Develop Students' Multicultural Counseling Competency. Journal of Multicultural Counseling and Development, 46(1), 40-57. https://doi.org/10.1002/jmcd.12091 